\author{
국내 조사료용 볏짚의 수확 전 작물포 및 수확 후 저장에 따른 \\ 곰팡이독소 오염 실태 연구 \\ 성 하 균* \\ 상지대학교, 원주 220-702
}

\title{
The Studies on Real Condition of Mycotoxin Contamination in the Fields before Harvest and by the Storage of Rice Straw using as Roughage in Korea Ha Guyn Sung*
}

Sangji University, Wonju, 220-702, Korea

\begin{abstract}
The studies were conducted to investigate real condition of mycotoxin contamination in the fields before harvest and by the storages of rice straw used as roughage in Korea. It was found mycotoxin contamination before harvest of rice straw that the rice plants were detected deoxynivalenol at the initial growth, ochratoxin $\mathrm{A}$ and deoxynivalenol at the middle growth, and deoxynivalenol and zearalenone at the harvest periods in the fields. Also, the rice plants were contaminated by various fungi such as Fusarium sp., Fusarium proliferatum, Penicillium sp., Gibberella sp., Gibberella zeae, Mucor circinelloides and Aspergillus oryzae. The levels of fungal contamination were $10^{3-4} \mathrm{cfu} / \mathrm{g}$ at the initial growth, and $10^{4-5} \mathrm{cfu} / \mathrm{g}$ at the middle growth and harvest periods. All storage types of rice straw were contaminated with zearalenone, deoxynivalenol and ochratoxins A. The samples of rice straw contaminating mycotoxins were account for 3\% in bundle rice straw, and $38 \%$ in both types of square rice straw and rice round bale silage, respectively. When 105 samples of rice bale silage were analyzed for mycotoxins depending on the regional area, mycotoxin contamination was found in $46 \%$ of total samples in Korea. Regional contaminations of mycotoxins were respectively 48, 33, 40, 50 and 57\% of samples in Gyeonggi, Gangwon, Chungcheng, Yeongnam and Honam area. Rice round bale silage was contaminated by three kinds of mycotoxins (zearalenone, deoxynivalenol and ochratoxinsA) in the all of area without Chungcheong area where was contaminated zearalenone and deoxynivalenol. Ochratoxins A, deoxynivalenol and zearalenone were respectively determinated with the average levels of $2.6,413$ and $338 \mu \mathrm{g} / \mathrm{kg}$ in rice round bale silage for the overall area, even if it was some difference depending on each regional area. Therefore, the above results clearly show that the rice straws were exposed to the contamination by mycotoxin and mycotoxigenic fungi before harvest in the fields, and mycotoxin contamination was not dependent on the regional area or the storage types such as bundle rice straw, square rice straw and rice round bale silage.
\end{abstract}

(Key words : Fungi, Mycotoxin, Rice straw)

\section{I. 서 론}

사료작물을 수확하기 전에 곰팡이 오염을 완전히 제어 할 수 있는 농작물 재배 기술이 아직 없어 가축의 사료에 곰팡이독소 오염은 피할 수 없는 실정이며, 곰팡이독소는 가축에게 다양한 좋지 않은 독성학적 증세들을 일으킨다 (D'mello and Macdonald, 1997; Jouany and Diaz, 2005). 이 들 곰팡이독소는 농산물우수관리제도(GAP, good agricultural practices) 및 우수제조관리기준 (GMP, good manufacturing practices) 하에서도 완전히 제거되지 않기 때문에 가축의 건강에 해를 주지 않는 수준인 아주 소량의 곰팡이독소는 사료에 유입을 법적으로 허용하고 있다. 따라서 많은 나라 들은 일정 사료에 허용 가능한 곰팡이독소와 농도를 규정 하여 규제해 오고 있으며, 최소 77 개 나라가 국제 무역간 곰팡이독소 규제에 참여하고 있다(CAST, 2003). 또한 우 리나라도 사료의 종류에 따라 aflatoxins $\left(\mathrm{B}_{1}, \mathrm{~B}_{2}, \mathrm{G}_{1}, \mathrm{G}_{2}\right)$ 과 ochratoxins $\mathrm{A}$ 에 한하여 규제하고 있다(사료관리법, 시행 2011).

* Corresponding author: Ha Guyn Sung, 5F Ireh-BLD, 139-1 Gasan-dong, Geumcheon-gu, Seoul, 153-801 Korea, Tel: +82-2-400-2901, Fax: +82-2-400-4901, E-mail: haguyn@hanmail.net 
전 세계적으로 작물의 $25 \%$ 정도가 매년 곰팡이독소의 영향을 받는 것으로 보고되고 있다(CAST, 1989). 미국의 경우는 작물에 곰팡이독소 오염에 의한 연간 잠정적 경제 적 손실을 4.18 16.6억 달러에 달하는 것으로 추정하고 있 다(CAST, 2003). Binder (2007)는 유럽 지역과 아태평양 지 역으로부터 수거된 사료와 사료 원료를 조사하였을 때 유 럽지역은 2,753 개 샘플 중 1,507 개 샘플에서 그리고 아태 평양 지역은 6,391 개 샘플 중 1,291 개 샘플에서 곰팡이독 소 양성 검출이 나타났다. 이들 곰팡이독소의 발생율과 농 도는 매년 변동이 심한데 이는 해마다 기상 상태와 곰팡이 발생과 관련된 식물 스트레스가 다르기 때문이다(Coulumbe, 1993).

사료 작물에 곰팡이독소는 수확하기 이전 생장, 추수 후 저장, 운송, 가공 또는 급여하는 기간 동안 발생 할 수 있 다(Scudamore and Livesey, 1998; Auerbach, 2003; FinkGremmels, 2005). 특히, 반추 동물에 급여되는 사일리지, 건초 및 짚 등의 조사료는 가축에게 급여하기까지 모든 과 정에서 곰팡이독소 오염에 쉽게 노출되어 있다. 이들 조사 료에 곰팡이독소 오염에 대한 심각성은 뉴질랜드, 미국, 유 럽뿐만 아니라 아시아권에서도 보고되고 있다 (Scudamore and Livesey, 1998; Binder, 2007). 이러한 곰팡이독소 오염 사료의 가축 섭취는 사료섭취량 감소, 사료 거부, 사료 효 율 저하, 낮은 증체, 면역 저하로 질병 발생 증가 및 번식 능력 저하를 가져오고(Fink-Gremmels and Malekinejad, 2007; Morgavi and Riley, 2007; Pestka, 2007; Voss et al., 2007), 이러한 영향은 경제적 손실을 초래하게 된다(Huwig et al., 2001; Wu, 2004; Wu, 2006). 미국의 경우는 곰팡이독 소로 인해 가축에게 발생하는 연간 잠정적 경제적 손실을 600 만 달러에 달하는 것으로 추정하고 있다(CAST, 2003).

국내 조사료의 자급도는 $80 \%$ 수준으로 이들에 대한 곰 팡이 오염 실태관련 조사연구가 아주 미비한 실정이다. 따 라서 본 연구는 국내에서 대표적 자급 조사료 자원인 볏짚 을 대상으로 곰팡이 오염 실태를 조사하기 위하여 벼의 생 육기간의 생장 단계별, 수확 후 볏짚의 보관 형태별 및 가 장 대표적 저장 방법인 곤포사일리지의 지역별 곰팡이독소 오염 실태를 조사하여 국내 곰팡이오염 연구의 기초 자료 를 제공하고자 실시하였다.

\section{ㅍ. 재료 및 방법}

\section{1. 생육기간 벼 및 저장 볏짚의 시료 준비}

국내에서 조사료용으로 사용하는 볏짚에 오염된 곰팡이
독소를 분석하기 위하여 생육 기간 동안 생장 단계별 벼와 수확 후 보관 중인 형태별 볏짚을 시험 목적에 따라 샘플 을 채취하여 $1 \mathrm{~cm}$ 길이로 세절하고 $4^{\circ} \mathrm{C}$ 에 냉장 보관하여 사용하였다.

벼의 생장 단계별 곰팡이독소 오염 정도를 분석하기 위 하여 생장 초기 (6월), 생장 중기 (8월), 그리고 수확기 (10 월)로 나누어 벼 샘플을 확보 하였다. 그리고 샘플 채취는 중부권 지역 2곳(이천시, 화성군)에서 일정 지역의 논을 선정하여 지정한 3 곳에서 시기별 벼를 채취하여 곰팡이독 소 분석을 위해 세절하여 보관 사용하였다. 그리고 일정량 의 샘플은 멸균된 커터기를 이용하여 세절하고 오염 곰팡 이의 분리 및 동정을 위한 샘플로 준비하였다.

볏짚의 보관 형태별 곰팡이독소 오염 상태를 비교 분석 하기 위하여 통 볏짚단, 사각 볏짚단 및 볏짚 곤포사일리 지로 나누어 각각 13 점씩 샘플을 확보하였다. 그리고 시료 는 수확하여 보관 사용 중인 볏짚으로 여름 우기가 지난 2010년 8월말부터 9월 사이에 충청과 호남 지역 소재 농가 에서 채취 사용하였다.

곰팡이독소의 지역별 볏짚에서 곰팡이독소 오염 상황을 조사하기 위하여 최근 가장 많은 볏짚의 저장 형태인 곤포 사일리지를 대상으로 경기, 강원, 충청, 호남 및, 영남으로 나누어 2년간(2009 2010년) 지역별 시료를 각각 20점 이 상씩 채취하여 총 105 점을 분석하여 조사하였다.

\section{2. 볏짚 시료의 mycotoxin 오염 분석}

묵음 볏짚단, 사각 볏짚단 및 볏짚 곤포사일리지에 오염 된 곰팡이독소는 냉장보관 시료를 HPLC를 이용하여 9종 의 mycotoxin 즉, aflatoxins $\left(\mathrm{B}_{1}, \mathrm{~B}_{2}, \mathrm{G}_{1}, \mathrm{G}_{2}\right)$, zearalenone, deoxynivalenol, fumonisin $\left(\mathrm{B}_{1}, \mathrm{~B}_{2}\right)$, ochratoxins $\mathrm{A}$ 등을 분석 하여 오염실태를 조사하였다.

곰팡이독소 추출은 $10 \mathrm{~g}$ 의 시료에 $20 \mathrm{ml}$ 의 acetonitrile을 가하여 30 분 동안 진탕 추출하였다. 그리고 $3,000 \mathrm{rpm}$ 에서 5 분간 원심분리를 하여 상층액을 분리하였다. 분리한 상층 액을 정제하기 위하여 추출한 상층액 $10 \mathrm{ml}$ 을 $\mathrm{Oasis}^{\circledR} \mathrm{HLB}$ SPE cartridge (Waters, USA)에 적용하고, 증류수로 cartridge 를 세척한 후 $6 \mathrm{ml}$ 의 $100 \%$ methanol을 사용하여 용출시켰 다. 용출된 시료를 $50^{\circ} \mathrm{C}$ 에서 $\mathrm{N}_{2}$ gas를 사용하여 건조하였 고, 건조된 시료를 methanol과 ammonium acetate $(10 \mathrm{mmol} /$ $\mathrm{L})$ 을 $1: 1(\mathrm{v} / \mathrm{v})$ 로 혼합한 용매 $(1 \mathrm{ml})$ 로 다시 용해하여 얻은 액상 시료를 분석에 사용하였다. 곰팡이 독소 중 aflatoxin, ochratoxin, zearalenone, fumonisin은 HPLC를 이용한 선행 연구 (Hammond et al., 2004; Akiyama et al., 2001; Caloni 
et al., 2000; Li et al., 1997; Xiao et al., 1996; Lerch and Muller, 1990; Vicam, 1988; Visconti and Pascale, 1998)에 서 사용한 방법을 기초로 fluorescence detector를 사용하여 분석하였다. 그리고 DON은 Mateo et al. (2001), Visconti and Battalico(1983)이 사용한 HPLC 방법을 기초로 UV detector를 사용하여 분석하였다.

\section{3. 볏짚 시료의 곰팡이 오염도 분석}

벼의 생육 단계별 곰팡이 오염 정도를 분석하기 위하여 생장 초기, 생장 중기, 그리고 수확기에 채취한 신선한 시 료를 $190 \mathrm{ml}$ 의 $0.85 \%$ 멸균 식염수가 들어 있는 $500 \mathrm{ml}$ 삼 각플라스크에 $10 \mathrm{~g}$ 을 넣고, $4^{\circ} \mathrm{C}$ 의 진탕기에서 $250 \mathrm{rpm}$ 으로 10 분간 진탕하여 곰팡이 포자들이 식염수에 부유하도록 하 였다. 그리고 삼각플라스크 상등액을 채취하여 $10^{2} \sim 10^{6}$ 이 되도록 멸균 식염수에 희석하고, 곰팡이 선별배지 (PDA)로 만든 agar plate에 도말하여 $25^{\circ} \mathrm{C}$ 에서 5 일 동안 배양하였다. 그리고 배양 기간 동안 매일 형성된 단일 콜로니를 관찰 및 계수하여 기록하였다. 그리고 곰팡이 오염도는 계수가 가능한 최대 단일 콜로니가 형성된 시기의 측정치를 사용 하였다.

\section{4. 볏짚 시료 발생 곰팡이의 분리 및 동정}

생육 단계별 벼에 발생한 곰팡이 종류를 분석하기 위하 여 곰팡이 오염도 분석을 위하여 배양 중인 agar plate를 매일 관찰하는 중에 형태학적으로 상이한 콜로니를 분리하 여 곰팡이 선별배지 $(\mathrm{PDA})$ 에서 단독 배양을 실시하였다. 그리고 순수 배양을 위하여 3회 이상 계대배양을 실시하여 순수한 single colony를 확보하였다.

순수 배양된 single colony는 $18 \mathrm{~S}$ rRNA의 분자생물학적 특성에 의해 동정되었다. 즉, 순수배양된 콜로니로부터 Total DNA를 추출하여 primer ITS1F (5'-CCTGGTCATT TAGAGGAAGTAA-3')과 ITS4 (5'-TCCTCCGCTTATTGATA TGC-3')을 이용하여 $18 \mathrm{~S}$ rRNA 부위를 Brookman et al. (2000)이 서술한 PCR 방법에 의하여 genomic DNA로부터 증폭하고, 증폭된 $\mathrm{DNA}$ 단편은 $\mathrm{pGEM}^{\circledR}-\mathrm{T}$ Easy vector system (Promega, USA)에 클로닝 하였으며, inset DNA를 dideoxy chaintermination method (Sanger et al., 1977)에 의 하여 염기서열을 결정하고, 얻어진 염기서열은 $\mathrm{NCBI}$ BLAST search를 이용하여 $18 \mathrm{~S}$ rRNA 염기서열의 특성에 의거하여 동정하였다.

\section{III. 결과 및 고찰}

\section{1. 생육기 벼의 곰팡이독소 및 곰팡이 발생}

사료 작물이 포장에서 자라는 동안 여러 종류의 곰팡이 에 의해 감염이란 위험에 노출되어 있으며 (Santin, 2005), 이들 중 일부 곰팡이들은 곰팡이독소를 분비하여 수확 후 또는 방목 시 가축에게 급여되어 가축에게 위해를 줄 수 있는 곰팡이 독소도 보고되고 있다 (Scudamore and Livesey, 1998). 따라서 본 볏짚이 수확하기 전 벼의 생육기간에 곰 팡이독소 및 곰팡이 발생 실태를 조사하기 위하여 중부권 의 일정 지역에서 벼의 생장 초기, 생장 중기 및 수확기에 오염 실태를 조사한 결과는 Table 1 그리고 2와 같다.

벼의 생장기간에 조사한 9가지 곰팡이 독소 중 ochratoxin A, deoxynivalenol 및 zearalenone이 오염된 것으로 발견 되었다(Table 1). 벼의 생육 단계별 곰팡이독소 오염수 준은 생장 초기에는 1 가지 독소가 오염되어 있었는데 deoxynivalenol이 $297 \mu \mathrm{g} / \mathrm{kg}(75 \sim 283 \mu \mathrm{g} / \mathrm{kg})$ 수준으로 발견되 었고, 생장 중기에는 2가지 독소가 오염되어 있었으며 ochratoxin A가 $1.8 \mu \mathrm{g} / \mathrm{kg}(1.5 \sim 2.1 \mu \mathrm{g} / \mathrm{kg})$ 수준으로 그리고 deoxynivalenol이 $264 \mu \mathrm{g} / \mathrm{kg}(299 \sim 429 \mu \mathrm{g} / \mathrm{kg})$ 수준으로 오염 되어 있었다. 그리고 수확기에는 deoxynivalenol이 $190 \mu \mathrm{g} /$ $\mathrm{kg}(59 \sim 320 \mu \mathrm{g} / \mathrm{kg})$ 과 zearalenone이 $168 \mu \mathrm{g} / \mathrm{kg}(118 \sim 218 \mu \mathrm{g} / \mathrm{kg})$ 으로 2가지 곰팡이 독소가 오염되어 있었다.

벼의 생장기에 발생한 곰팡이 오염 수준은 Table 2와 같 이 생장 초기에는 $10^{3-4} \mathrm{cfu} / \mathrm{g}$ 그리고 생장 중기와 추수기 에는 $10^{4-5} \mathrm{cfu} / \mathrm{g}$ 이었다. 그리고 생장 중인 볏짚에 오염된 곰팡이를 분리 배양하여 $18 \mathrm{~S} \mathrm{rRNA}$ 유전자 분석을 통한 동정결과, 초기에는 Fusarium sp.와 Mucor circinelloides가 발견되었고, 중기에는 Fusarium sp., Fusarium proliferatum, Penicillium sp., Gibberella zeae, Gibberella sp., Aspergillus oryzae 등 다양한 종류의 곰팡이가 발견되었다. 그리고 수 확기에는 Aspergillus sp. Aspergillus oryzae 및 Fusarium $\mathrm{sp}$. 등이 발견되었고, Fusarium sp.은 생장 초기 및 중기 그리고 수확기 모두 발견되었다.

CAST (1989)에서는 전 세계 작물의 $25 \%$ 정도가 해마다 곰팡이독소 영향을 받는 것으로 보고해 오고 있으며, 벼의 주산지는 태평양권 동아시아로 이 지역에서 생산된 벼의 짚과 사일리지 그리고 쌀과 왕겨에서도 본 연구와 같이 ochratoxin A, deoxynivalenol 및 zearalenone (Table 1) 뿐만 아니라 aflatoxins $\mathrm{B}_{1}$, fumonisin, $\mathrm{T}-2$ toxin의 오염 심각성에 대하여 보고한 바 있다. 본 연구의 벼 생장기에 발견된 deoxynivalenol 및 zearalenone는 곰팡이독소 생성 곰팡이 
Table 1. Mycotoxin contamination of rice plant in the periods of growth

(Unit : $\mu \mathrm{g} / \mathrm{kg})$

\begin{tabular}{lcccc}
\hline Mycotoxin & $\begin{array}{c}\text { Initial of growth } \\
\text { (June) }\end{array}$ & $\begin{array}{c}\text { Middle of growth } \\
\text { (August) }\end{array}$ & $\begin{array}{c}\text { Harvest stage } \\
\text { (October) }\end{array}$ & Average \\
\hline \hline Aflatoxin $\mathrm{B}_{1}$ & - & - & - & - \\
Aflatoxin $\mathrm{B}_{2}$ & - & - & - & - \\
Aflatoxin $\mathrm{G}_{1}$ & - & - & - & - \\
Aflatoxin $\mathrm{G}_{2}$ & - & - & - & - \\
Ochratoxin A & - & $(1.5-2.1)$ & - & $(1.5-2.1)$ \\
Fumonisin $\mathrm{B}_{1}$ & - & - & - & - \\
Fumonisin $\mathrm{B}_{2}$ & - & - & 190 & - \\
Deoxynivalenol & 279 & 264 & $(59-320)$ & 278 \\
Zearalenone & $(275-283)$ & $(229-299)$ & $(118-218)$ & $(59-429)$ \\
\hline
\end{tabular}

( ) : minimum to maximum value of mycotoxin.

Table 2. Fungal contamination on rice plant in the periods of growths

\begin{tabular}{|c|c|c|c|}
\hline Items & $\begin{array}{l}\text { Initial of growth } \\
\text { (June) }\end{array}$ & $\begin{array}{l}\text { Middle of growth } \\
\text { (August) }\end{array}$ & $\begin{array}{l}\text { Harvest stage } \\
\text { (October) }\end{array}$ \\
\hline $\begin{array}{l}\text { Fungal contamination } \\
\text { (cfu/g) }\end{array}$ & $10^{3-4}$ & $10^{4-5}$ & $10^{4-5}$ \\
\hline Fungal species & $\begin{array}{l}\text { Fusarium sp. } \\
\text { Mucor circinelloides } \\
\text { Unknown } 4 \text { strains }\end{array}$ & $\begin{array}{l}\text { Fusarium sp. } \\
\text { Fusarium proliferatum } \\
\text { Penicillium sp. } \\
\text { Gibberella zeae } \\
\text { Gibberella sp. } \\
\text { Aspergillus oryzae } \\
\text { Unknown } 3 \text { strains }\end{array}$ & $\begin{array}{l}\text { Aspergillus sp. } \\
\text { Aspergillus oryzae } \\
\text { Fusarium sp. } \\
\text { Unknown } 2 \text { strains }\end{array}$ \\
\hline
\end{tabular}

중 Fusarium sp.에 의해 생성되는 독소들이고, ochratoxin $\mathrm{A}$ 는 Penicillium sp.에 의하여 생성되는 독소 중 하나이다 (Scudamore and Livesey. 1998; Auerbach, 2003). Fusarium $\mathrm{sp}$.는 필드 곰팡이의 대표적 곰팡이독소 생성 곰팡이 중 하나이며 (Santin, 2005), Lee (2009)의 우리나라 벼에 오염 되어 있는 Fusarium sp. 군락의 유전적 다양성에서도 보고 된 바 있다. 그리고 Desjardins et al. (2000)은 네팔의 벼에 서 질병과 독소를 생성하는 Fusarium sp.을 비롯한 다른 종류의 곰팡이를 보고 하였고, Lesli and Summerell (2006) 은 벼에서뿐만 아니라 보리 및 밀에서도 발생함을 보고하 였다. 그리고 본 연구에서 곰팡이독소가 발견된 벼의 생장 기에 Fusarium sp.과 Penicillium sp.이 오염 되어 있었음을 확인 할 수 있었고 (Table 2), 다른 볏짚 연구 (Pillips et al., 1996; Phillips and Wareing, 1993)에서도 이들에 대하여 보 고된 바 있다. 또한 본 연구에서 벼의 생장기에 aflatoxin 검출이 안됐지만 Aspergillus 종의 군락이 오염되어 있음이 확인되었고, Aspergillus oryzae를 제외한 Aspergillus sp. 중
에는 반추가축의 생산성 감소를 일으킬 뿐만 아니라 우유 에 전이되는 aflatoxins $\mathrm{B}_{1}$ 을 분비하는 것으로 알려진 Aspergillus flavus도 있다(Bhuiyan et al., 2003; Jouany and Diaz, 2005). 이상의 연구 보고와 함께 본 연구는 우리나라 볏짚도 벼를 수확하기 전에 축우에게 해로운 곰팡이독소 및 곰팡이들의 오염 가능성을 충분히 시사하고 있다. 또한 이들 작물은 생장기 동안 기후, 온도 및 습도의 환경적 요 인과 병충으로부터 손상 정도 및 작물의 스트레스 등의 조 건에 따라 그 오염 정도가 심각해 질 수도 있음을 간과해 서는 안 될 것이다.

\section{2. 볏짚의 저장형태에 따른 곰팡이독소 오염}

가축에게 실제 급여하고 있는 조사료용 볏짚의 저장 방 법에 따른 오염된 mycotoxin을 조사하기 위하여 충청 및 호남지역의 농가에서 채취한 시료를 분석한 결과는 Table 3 과 같다. 
Table 3. Mycotoxin contamination of rice straw with storage types

(Unit: $\mu \mathrm{g} / \mathrm{kg}$ )

\begin{tabular}{lcccc}
\hline \multicolumn{1}{c}{ Mycotoxin } & Bundle rice straw & Square rice straw & Round bale silage & Average \\
\hline \hline Contamination ratio (\%) & 23 & 38 & 38 & 33 \\
Aflatoxin $\mathrm{B}_{1}$ & - & - & - & - \\
Aflatoxin $\mathrm{B}_{2}$ & - & - & - & - \\
Aflatoxin $\mathrm{G}_{1}$ & - & - & - & - \\
Aflatoxin $\mathrm{G}_{2}$ & - & - & - & - \\
Ochratoxin A & - & 2.3 & $(2.4 \sim 3.8)$ & $(1.9 \cdot 3.8)$ \\
Fumonisin $\mathrm{B}_{1}$ & - & $(1.9 \sim 2.7)$ & - & - \\
Fumonisin $\mathrm{B}_{2}$ & - & - & - & - \\
Deoxynivalenol & 371 & - & 480 & 369 \\
Zearalenone & $(242 \sim 500)$ & $(200 \sim 310)$ & $(273 \sim 687)$ & $(200 \sim 687)$ \\
\hline
\end{tabular}

( ) : minimum to maximum value of mycotoxin.

본 연구에 조사된 볏짚 샘플에서는 aflatoxins $\left(\mathrm{B}_{1}, \mathrm{~B}_{2}, \mathrm{G}_{1}\right.$, $\left.\mathrm{G}_{2}\right)$ 과 fumonisin $\left(\mathrm{B}_{1}, \mathrm{~B}_{2}\right)$ 은 검출 되지 않았지만 zearalenone, deoxynivalenol 및 ochratoxins $\mathrm{A}$ 가 검출되었다. 먼저 전통 적 보관 방법인 통 볏짚단의 곰팡이독소 오염도는 $23 \%$ 이 었고, 사각 볏짚단과 곤포사일지지는 각각 $38 \%$ 비율로 오 염되어 있었다. 통 볏짚단은 2가지 곰팡이독소 즉, deoxynivalen이 $371 \mu \mathrm{g} / \mathrm{kg}(242-500 \mu \mathrm{g} / \mathrm{kg})$ 수준으로 그리고 zearalenone은 $317 \mu \mathrm{g} / \mathrm{kg}(290-344 \mu \mathrm{g} / \mathrm{kg})$ 수준으로 오염되었 다. 사각 볏짚단에서는 ochratoxins A가 $2.3 \mu \mathrm{g} / \mathrm{kg}(1.9-2.7 \mu \mathrm{g}$ $/ \mathrm{kg}$ ), deoxynivalenol이 2,551 $\mathrm{gg} / \mathrm{kg}(200-310 \mu \mathrm{g} / \mathrm{kg})$ 및 zearalenone 이 $514 \mu \mathrm{g} / \mathrm{kg}(235-750 \mu \mathrm{g} / \mathrm{kg})$ 수준으로 3 가지 곰팡이 독소가 오염되어 있었다. 또한 곤포사일리지도 3 가지 곰팡이독소 가 오염되어 있었는데 ochratoxins A가 $3.1 \mu \mathrm{g} / \mathrm{kg}(2.4-3.8 \mu \mathrm{g}$ $/ \mathrm{kg}$ ) 수준으로 검출되었고, deoxynivalenol 및 zearalenone은 각각 $480 \mu \mathrm{g} / \mathrm{kg}(273-687 \mu \mathrm{g} / \mathrm{kg})$ 및 zearalenone이 $303 \mu \mathrm{g} / \mathrm{kg}$ $(235-370 \mu \mathrm{g} / \mathrm{kg})$ 수준에서 오염되어 있었다.

본 연구 결과와 같이 수확 후 보관 및 저장 볏짚의 곰팡 이독소 오염의 심각성에 대하여 여러 연구에서 보고하고 있다(Phillips et al., 1996; Mamun et al., 2002; Bhuiyan et al., 2003). Binder et al. (2007)은 짚과 사일리지의 두 형태 모두에서 ochratoxin A, deoxynivalenol, zearalenone, aflatoxins B 및 fumonisin의 오염에 노출되어 있음을 보고 하였다. 그리고 Mamun et al. (2002)은 볏짚 20점에 대하 여 fumonisin과 aflatoxins을 분석하였을 때 본 연구에서는 검출되지 않았지만 fumonisin 오염에 대하여 보고하였고, Bhuiyan et al. (2003)는 볏짚을 급여한 젖소의 우유에서 aflatoxin $\mathrm{M}_{1}$ 이 검출 되었다고 보고한 바 있다. 그리고 본 연구에 사용된 샘플에서 Fusarium sp.에 의해 생성되는 zearalenone 및 deoxynivalenol과 함께 Penicillium sp.에 의 하여 생성되는 ochratoxins A가 검출되었는데 이들 곰팡이 는 볏짚에서 Aspergillus sp.와 함께 가장 많이 오염되는 곰 팡이 종류라는 것이 보고된바 있다(Phillips and Wareing, 1993; Phillips et al., 1996).

또한 본 연구에서도 저장 형태에 상관없이 모든 볏짚에 서 곰팡이독소가 검출되었는데 Lacey (1991)는 사료작물이 생장하는 포장에서뿐만 아니라 건초 또는 사일리지와 같은 저장 중에도 다양한 많은 곰팡이독소가 발생함을 보고한바 있다. 이는 사료 작물이 수확되어 저장되어도 오염된 곰팡 이독소는 파괴되지 않고 계속 남아 있기 때문이며, 짚과 건초의 건조 상태가 좋지 못해 $15 \%$ 이하의 수분 함량을 유지하지 못할 경우 또는 사일리지가 기밀 상태를 유지 못 하고 공기의 유입이 발생하는 경우 곰팡이 독소는 더 가중 될 수 있음이 보고된바 있다(Scudamore and Livesey, 1998; Auerbach, 2003).

\section{3. 지역별 볏짚 곤포사일지의 곰팡이독소 오염}

잘 저장된 사일리지는 곰팡이의 성장이 어려우나 공기의 유입은 곰팡이 발생과 곰팡이독소 오염을 일으키는 주요 원인이 되고 있고(Scudamore and Livesey, 1998), 사일리지 의 곰팡이독소 오염 문제에 대하여 여러 연구에서 보고되 고 있다(Auerbach, 2003; Mansfield et al., 2005). 따라서 국내 볏짚 곤포사일리지의 곰팡이독소 오염 실태를 조사하 고자 2년간(2009 2010년) 농가 및 TMR 공장에서 사용하 고 있는 것을 수거하여 조사한 결과는 Table 4 그리고 5 와 같다. 
Table 4 . The ratio of round bale rice straw silage contaminated by mycotoxin

\begin{tabular}{lccccc}
\hline \multirow{2}{*}{ Region } & $\begin{array}{c}\text { Analysed sample } \\
\text { No. }\end{array}$ & Sample ratio & $\begin{array}{c}\text { More than one } \\
\text { kind }\end{array}$ & $\begin{array}{c}\text { More than tow } \\
\text { kinds }\end{array}$ & $\begin{array}{c}\text { More than three } \\
\text { kinds }\end{array}$ \\
\cline { 3 - 6 } Gyeonggi & 23 & 48 & 39 & 4 & 0 \\
Gangwon & 21 & 33 & 33 & 14 & 0 \\
Chungcheong & 20 & 40 & 40 & 10 & 0 \\
Yeongnam & 20 & 50 & 50 & 25 & 0 \\
Honam & 21 & 57 & 57 & 24 & 5 \\
Overall value & 105 & 46 & 44 & 15 & 1 \\
\hline
\end{tabular}

Table 5. Mycotoxin contamination of round bale rice straw silage with region

\begin{tabular}{|c|c|c|c|c|c|c|}
\hline Mycotoxin & Gyeonggi & Gangwon & Chungcheong & Yeongnam & Honam & Overall value \\
\hline Aflatoxin $\mathrm{B}_{1}$ & - & - & - & - & - & - \\
\hline Aflatoxin $\mathrm{B}_{2}$ & - & - & - & - & - & - \\
\hline Aflatoxin $\mathrm{G}_{1}$ & - & - & - & - & - & - \\
\hline Aflatoxin $\mathrm{G}_{2}$ & - & - & - & - & - & - \\
\hline Ochratoxin A & $(1.7 \sim 2.5)$ & $(1.3 \stackrel{2.0}{\sim} 2.7)$ & & $\begin{array}{c}2.3 \\
(1.4 \sim 3.5)\end{array}$ & $(1.2 \stackrel{3.0}{\sim} 5.8)$ & $\left(1.2^{2.6} \sim 5.8\right)$ \\
\hline \multicolumn{7}{|l|}{$\begin{array}{l}\text { Fumonisin } \mathrm{B}_{1} \\
\text { Fumonisin } \mathrm{B}_{2}\end{array}$} \\
\hline Deoxynivalenol & $\begin{array}{c}249 \\
(59 \stackrel{429}{\sim})\end{array}$ & $\begin{array}{c}433 \\
(165 \sim 687)\end{array}$ & 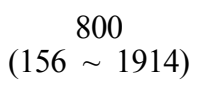 & $\begin{array}{c}246 \\
(150 \sim 321)\end{array}$ & $\begin{array}{c}380 \\
(260 \sim 500)\end{array}$ & $\begin{aligned} & 413 \\
(59 & \sim 1914)\end{aligned}$ \\
\hline Zearalenone & $\begin{array}{c}168 \\
(103 \sim 235)\end{array}$ & $\begin{array}{c}467 \\
(233 \sim 847)\end{array}$ & $\begin{array}{c}270 \\
(38 \sim 501)\end{array}$ & $\begin{array}{c}328 \\
(125 \sim 750)\end{array}$ & $\begin{array}{c}442 \\
(106 \sim 776)\end{array}$ & $\begin{array}{c}338 \\
(38 \sim 847)\end{array}$ \\
\hline
\end{tabular}

( ) : minimum to maximum value of mycotoxin.

우리나라 볏짚 곤포사일리지의 곰팡이 오염 실태는 Table 4에서와 같이 전국적으로 105 점을 조사하였을 때 $46 \%$ 의 샘플에서 곰팡이독소 오염을 발견하였고, 지역적으 로는 경기, 강원, 충청, 영남 및 호남지역에서 각각 48,33 , 40, 50 및 $57 \%$ 의 샘플이 곰팡이독소에 오염되어 있었다. 조사된 볏짚 곤포사일리지 중에서 단일 곰팡이독소에 오염 된 샘플은 $44 \%$ 에 달하였고, 곰팡이독소 두 가지가 복합적 으로 오염된 샘플은 $15 \%$ 를 차지하였다. 그리고 3 가지가 복합적으로 오염된 샘플은 전국적으로 $1 \%$ 이었고, 호남지역 의 샘플에서 발견되었다. 조사된 볏짚 곤포사일리지에서 오염된 곰팡이독소는 3가지로 zearalenone, deoxynivalenol 및 ochratoxins A가 측정되었고, aflatoxins와 fumonisin은 측정되지 않았다 (Table 5). 지역적으로는 2가지 곰팡이독소 (zearalenone과 deoxynivalenol)가 오염된 충청지역을 제외하 고는 모든 지역에서 3 가지의 곰팡이독소가 발견 되었다. Oochratoxins A의 오염 수준은 전체적으로 $2.6 \mu \mathrm{g} / \mathrm{kg}(1.2-$ $5.8 \mu \mathrm{g} / \mathrm{kg}$ )으로 충청지역에서는 발견되지 않았지만 강원지 역이 $2.0 \mu \mathrm{g} / \mathrm{kg}(1.3-2.7 \mu \mathrm{g} / \mathrm{kg})$ 으로 가장 낮았고, 호남지역이 $3.0 \mu \mathrm{g} / \mathrm{kg}(1.2-5.8 \mu \mathrm{g} / \mathrm{kg})$ 으로 다른 지역보다 높았다. Deoxy- nivalenol의 오염 수준은 전체적으로 $413 \mu \mathrm{g} / \mathrm{kg}(59-1,914 \mu \mathrm{g} /$ $\mathrm{kg})$ 으로 충청지역이 $800 \mu \mathrm{g} / \mathrm{kg}(156-1,914 \mu \mathrm{g} / \mathrm{kg})$ 로 가장 높 았고, 다른 지역은 $246 \mu \mathrm{g} / \mathrm{kg}$ 에서 $433 \mu \mathrm{g} / \mathrm{kg}$ 의 수준으로 발 견되었다. 그리고 Zearalenone은 전체적으로 $338 \mu \mathrm{gg} / \mathrm{kg}$ $(38-847 \mu \mathrm{g} / \mathrm{kg})$ 으로 경기지역이 $168 \mu \mathrm{g} / \mathrm{kg}(103-235 \mu \mathrm{g} / \mathrm{kg})$ 로 다른 지역보다 낮았고, 강원과 호남지역이 각각 $467 \mu \mathrm{g} / \mathrm{kg}$ $(233-847 \mu \mathrm{g} / \mathrm{kg})$ 과 $442 \mu \mathrm{g} / \mathrm{kg} \quad(106-776 \mu \mathrm{g} / \mathrm{kg})$ 으로 높았다.

Binder et al. (2007)은 볏짚사일리지를 포함한 사료의 조 사 샘플 중에서 곰팡이독소 양성을 보인 샘플이 전 세계적 으로 $52 \%$ 그리고 아시아에서는 $30 \%$ 에 달하였다고 보고 하였다. 그리고 Russell et al. (1991)은 미국 6개주를 대상으 로 옥수수의 곰팡이독소 오염을 조사하였을 때 본 연구의 결과와 같이 어느 지역에 국한되어 곰팡이독소가 오염된 것이 아니라 전 지역에 걸쳐 오염 현상이 나타남을 보고하 였고, Mamun et al.(2002)도 방글라데시의 두 지역을 대상 으로 볏짚의 곰팡이독소 오염을 조사하였을 때 fumonisin 오염이 지역 간 큰 차이 없이 발견됨을 보고한 바 있다. 또한 Binder et al. (2007)은 본 연구와 같이 볏짚 사일리지 에서 zearalenone, deoxynivalenol 및 aflatoxin $\mathrm{B}_{1}$ 의 오염을 
보고하였고, 이외에 여러 연구에서 옥수수, 보리, 밀, 콩 및 목초 등의 다양한 원료의 사일리지에서도 공팡이독소 오염 이 계속적으로 보고되고 있다 (Smith et al., 1973; Auerbach et al., 1998; Scudamore and Livesey, 1998; Fink-Gremmels, 2005; Mansfield and Kulau, 2007). 이상의 연구 결과는 사 일리지의 종류 및 지역에 상관없이 곰팡이독소가 사일레지 에 오염되어 있을 수 있음을 보여준다. 따라서 안전하고 질 좋은 조사료를 확보하기 위해서는 이들의 오염 경로 및 실태에 대한 더 구체적 연구와 대책 마련을 위한 탐구가 지속적으로 이루어져야 할 것으로 사료된다.

$$
\text { IV. 요 약 }
$$

본 연구는 국내 생산 볏짚의 곰팡이독소 오염 실태를 파 악하기 위하여 벼의 생육 단계별, 볏짚의 보관 형태별 및 곤포사일리지의 지역별 오염을 조사하였다. 수확하기 전 논에서 생장 중인 벼에서 곰팡이독소 및 곰팡이 오염이 확 인되었다. 벼의 생장 초기에는 deoxynivalenol $(297 \mu \mathrm{g} / \mathrm{kg})$ 이 발견되었고, 중기에는 ochratoxin $\mathrm{A}(1.8 \mu \mathrm{g} / \mathrm{kg})$ 및 deoxynivalenol $(264 \mu \mathrm{g} / \mathrm{kg})$ 이 오염되어 있었다. 그리고 수확시기 에는 deoxynivalenol $(190 \mu \mathrm{g} / \mathrm{kg})$ 및 zearalenone $(168 \mu \mathrm{g} / \mathrm{kg})$ 이 오염되어 있었다. 그리고 곰팡이 오염은 생장 초기에는 $10^{3-4}$ $\mathrm{cfu} / \mathrm{g}$ 그리고 생장 중기와 수확시기에는 $10^{4-5} \mathrm{cfu} / \mathrm{g}$ 이었다. 오염된 곰팡이로는 Fusarium sp., Fusarium proliferatum, Penicillium sp., Gibberella sp., Gibberella zeae, Mucor circinelloides, Aspergillus oryzae 등 다양한 종류가 발견되 었다. 사료용 볏짚의 통 볏짚단, 사각 볏짚단 및 곤포사일 지 등 저장 방법에 따른 오염된 mycotoxin을 조사하였을 때 zearalenone, deoxynivalenol 및 ochratoxins A가 검출되 었다. 통 볏짚단의 곰팡이독소 오염도는 $23 \%$ 이었고, 사각 볏짚단과 곤포사일지지는 각각 $38 \%$ 가 오염되어 있었다. 그 리고 105 점의 볏짚 곤포사일리지에서 곰팡이독소를 분석하 였을 때 $46 \%$ 의 샘플에서 곰팡이독소가 발견되었고, 지역적 으로는 경기, 강원, 충청, 영남 및 호남지역에서 각각 48 , $33,40,50$ 및 $57 \%$ 의 샘플이 오염되어 있었다. 2 가지의 곰 팡이독소 (zearalenone, deoxynivalenol)가 발견된 충청지역을 제외한 모든 지역의 볏짚 곤포사일리지에서 3 가지의 곰팡 이독소 (zearalenone, deoxynivalenol, ochratoxins A)가 발견 되었다. Ochratoxins A의 오염 수준은 전체적으로 $2.6 \mu \mathrm{g} /$ $\mathrm{kg}$ 으로 충청지역에서는 발견되지 않았지만 호남지역은 3.0 $\mu \mathrm{g} / \mathrm{kg}$ 으로 다른 지역보다 높았다. Deoxynivalenol의 오염 수준은 전체적으로 $413 \mu \mathrm{g} / \mathrm{kg}$ 으로 충청지역이 $800 \mu \mathrm{g} / \mathrm{kg}$ 로 가장 높았고, 다른 지역은 $246 \mu \mathrm{g} / \mathrm{kg}$ 에서 $433 \mu \mathrm{g} / \mathrm{kg}$ 의 수준
으로 발견되었다. 그리고 zearalenone은 전체적으로 $338 \mu \mathrm{g} /$ $\mathrm{kg}$ 으로 경기지역이 $168 \mu \mathrm{g} / \mathrm{kg}$ 로 다른 지역보다 낮았고, 강 원과 호남지역이 각각 $467 \mu \mathrm{g} / \mathrm{kg}$ 과 $442 \mu \mathrm{g} / \mathrm{kg}$ 으로 높았다. 이상의 연구 결과는 볏짚은 수확하기 전 벼의 생장 기간에 도 곰팡이독소 및 곰팡이 오염에 노출되어 있으며, 볏짚의 보관 형태 및 지역에 상관없이 곰팡이독소의 오염이 발생 할 수 있음을 명확히 시사한다. 따라서 안전하고 질 좋은 조사료를 확보하기 위해서는 이들 곰팡이독소 관련 더 구 체적 연구와 대책관련 탐구가 지속적으로 이루어져야 할 것으로 사료된다.

\section{VI. 인 용 문 헌}

Akiyama, H., Goda, Y., Tanaka, T. and Toyoda, M. 2001. Determination of aflatoxins $B_{1}, B_{2}, G_{1}$ and $G_{2}$ in spices using a multifunctional column clean-up. Journal of Chromatography. 932:153-157.

Auerbach, H., Oldenburg, E. and Weissbach, F. 1998. Incidence of Penicillium roquiforti and Roquefortine $\mathrm{C}$ in silages. Journal of the Science of food and Agriculture. 76:565-572.

Auerbach, H. 2003. Mould growth and mycotoxin contamination of silage: sources, types and solution. In: Nutritional Biotechnology in the Feed and Food Industries (T.P. Lyons and K.A. Jacques). Nottingham Univ. Press, United Kingdom. pp. 247-265.

Bhuiyan, A., Akbar, M.A. and Hossain, M.E. 2003. Nutritive value of damp rice straw and its feeding effect on aflatoxin transmission into cows milk. Pakistan Journal of Nutrition. 2: 153-158.

Binder, E.M., Tan, L.M., Chin, L.J., Handl, J. and Richard, J. 2007. Worldwide occurrence of mycotoxins in commodities, feeds and feed ingredients. Animal Feed Science and Technology. 137: 265-282.

Brookman, J.L., Mennim, G., Trinci, A.P.J., Theodorou, M.K. and Tuckwell, D.S. 2000. Identification and characterization of anaerobic gut fungi using molecular methodologies based on ribosomal ITS1 and 18SrRNA. Microbioloy. 145:393-403.

Bruegel, P. 2002. Mycotoxins: Lisks in Plant, Animal and Human Systems. Council for Agricultural Science and Technology. USA. pp. 104-128.

Caloni, F., Spotti, M., Auerbach, H., Op den camp, H., Gremmels, J.F. and Pompa, G. 2000. In vitro metabolism of fumonisin $\mathrm{B}_{1}$ by ruminal microflora. Veterinary Research Communications. 24:379-387.

CAST (Council for Agricultural Science \& Technology). 1989. Mycotoxins: Economics and health risks. Task Force Report No. 
116. Ames, Iowa.

CAST (Council for Agricultural Science \& Technology). 2003. Mycotoxins: Lisks in Plant, Animal and Human Systems. Task Force Report No. 139. Ames, Iowa

Coulombe, Jr. A.C. 1993. Symposium: Biological action of mycotoxins. Journal of dairy science. 79:880-891.

Desjardins, A.E., Manandhar, H.K., Platter, R.D., Manadhar, G.G., Poling, S.M. and Maragos, C.M. 2000. Fusarium species Nepalese rice and production of mycotoxins and gibberellic acid by selected species. Applied and Environmental Microbiology. 66:1020-1025.

D'mello, J.P.F. and Macdonald, A.M.C. 1997. Mycotoxins. Animal Feed Science and Technology. 69:155-166.

Fink-Gremmels, J. 2005. Mycotoxin in forages. In: The Mycotoxin Blue Book. (D. E. Diaz). Nottingham Univ. Press, United Kingdom. pp. 249-268.

Fink-Gremmels, J. and Malekinejad, H. 2007. Clinical effects and biochemical mechanisms associated with exposure to the mycoestrogen zearalenone. Animal Feed Science and Technology. 137:326-341.

Hammond, B.G., Campbell, K.W., Pilcher, C.D., Degooyer, T.A., Robinson, A.E., McMillen, B.L., Spangler, S.M., Riordan, S.G., Rice, L.G. and Richard, J.L. 2004. Lower fumonisin mycotoxin levels in the grain of Bt corn grown in the Unite State in 2000-2002. Journal of Agricultural and Food Chemistry. 52: 1390-1397.

Huwig, A., Freimund, S., Kappeli, O. and Dutler, H. 2001. Mycotoxin detoxication of animal feed by different adsorbents. Toxicology Letters. 122:179-188.

Jouany, J.P. and Diaz, D.E. 2005. Effects of mycotoxins in ruminants. pp. 295-321 In: The Mycotoxin Blue Book. D.E. Diaz. Nottingham Univ. Press, United Kingdom.

Lacey, I. 1991. Natural occurrence of mycotoxins in growing and conserved forage crops. In: J.E. Smith and R.E. Henderson (Eds.). Mycotoxin and Animal Foods. CRC Press, Boca Raton, Fla. pp. 363-397.

Lee, J., Chang, I.Y., Kim, H., Yun, S.H., Leslie, J.F. and Lee, Y.W. 2009. Genetic diversity and fitness of Fusarium graminearum populations from rice in Korea. Applied and Environmental Microbiology. 75:3289-3295.

Leslie, J.F. and Summerell, B.A. 2006. The Fusarium laboratory manual. Blackwell Publishing Professional, Ames, Iowa. USA.

Lerch, C.M. and Muller, H.M. 1990. Analysis of ochratoxins from buffered rumen fluid by reverse-phase high performance fluid chromatograph (HPLC). Chromatographia. 30:424-427.

Li, S.R., Marquardt, R., Frohlich, A.A., Vitti, T.G. and Crow, G.
1997. Pharmacokinetics of ochratoxin A and its metabolites in rats. Toxicology and Applied Pharmacology. 145:82-90.

Mannum, M.A., Akbar, M.A. and Shahjalal, M. 2002. Rice straw, it's quality and quantity as affected by storage systems in bangladesh. Pakistan Journal of Nutrition. 1:153-155.

Mansfield, M.A., De Wolf, E.D. and Kuldau, G.A. 2005. Relationships between weather conditions, agronomic practices, and fermentation characters with deoxinivalenol content in fresh and ensiled maize. Plant Disease. 89:1151-1157.

Mansfield, M.A. and Kuldau, G.A. 2007. Microbiological and molecular determination of mycobiota in fresh and ensiled maize silage. Mycologia. 99:269-278.

Mateo, J.J., Liorens, A., Mateo, R. and Jimenez, M. 2001. Critical study of and improvements in chromatographic methods for the analysis of type B trichothecenes. Journal of Chromatography. 918:99-112.

Morgavi, D. and Riley, R.T. 2007. An historical overview of field disease outbreaks known or suspected to be caused by consumption of feeds contaminated with Fusarium toxins. Animal Feed Science and Technolchnology. 137:201-212.

Pestka, J.J. 2007. Deoxynivalenol: toxicity, mechanisms and health risks. Animal Feed Science and Technolchnology. 137:283-298.

Phillips, S. and Wareing, P. 1993. Mycological analysis of rice straw samples collected in bangladesh. File Note ProjectAO317. Natural Resources Institute, Chatham Marham Maritime, UK.

Phillips, S.I., Wareing, P.W., Dutta, A., Panigrahi, S. and Mediock, V. 1996. The mycoflora and incidence of mycotoxin, zearalenine and sterigmatocystin in dairy feed and forage samples from Eastern India and Bangladesh. Mycopathologia. 5:1-7.

Russell, L., Cox, D.F., Larsen, G., Bodwell, K. and Nelson, C.E. 1991. Incidence of molds and mycotoxins in commercial animal feed mills in seven midwestern states. Journal of Animal Science. 69:5-12.

Sanger, F., Nicklen, S. and Coulson, A.R. 1977. DNA sequencing with chain-terminating inhibitors. Proceedings of the National Academy of Sciences, USA. 74:5463-5464.

Santin, E. 2005. Mould growth and mycotoxin production. In: The Mycotoxin Blue Book (D.E. Diaz ed.). Nottingham Univ. Press, United Kingdom. pp. 225-234.

Scudamore, K.A. and Livesey, C.T. 1998. Occurrence and significance of mycotoxins in forage crops and silage; a review. Journal of the Science of Food and Agriculture. 77:1-17.

Smith, D.F. and Lynch, P.L. 1973. Aspergillus fumigatus in sample of moldy silage. Journal of Dairy Science. 56:828-829.

Vicam, L.P. 1998. VICAM zearalatest intruction mannual. Vicam, Watertown, MA, USA. 
Visconti, A. and Pascale, M. 1998. Determination of zearalenone in corn by means of immunoaffinity clean-up and high-performance liquid chromatography with fluroscence detection. Journal of Chromatography. 815:133-140.

Visconti, A. and Battalico, A. 1983. Detection if Fusarium trichothecens (nivalenol, deoxynivalenol, fusarenone and 3actyldeoxynivalenol) by high-performance liquid chromatography. Chromatographia. 17:97-100.

Voss, K.A., Smith, G.W. and Haschek, W.M. 2007. Fumonisins: Toxicokinetics, mechanism of action and toxicity. Animal Feed Science and Technology. 137:299-325.

$\mathrm{Wu}$, F. 2004. Mycotoxins risk assesment for the purpose of setting international regulatory standard. Environmental Science \&
Technology. 38:4049-4055

$\mathrm{Wu}, \quad$ F. 2006. Economic impact of fumonisin and aflatoxin regulations on global corn and peanut markets. In: Barug, D., Bhatnager, D., van Egmond, H.P., van der Kamp, J.W., van Osenbruggen, W.A., Viscinti, A. (Eds.), The Mycotoxin Factbook. Food \& Feed Topics. Wageningen Academic Publishers, The Netherlands.

Xiao, H., Marquardt, R.R., Abramson, D. and Frohlich, A.A. 1996. Metabolites of ochratoxins in rat urine and a culture of Aspergillus ocharaceus. Applied and Environmental Microbiology. 62:648-655

사료관리법. [시행 2011. 1. 1]. [법률 제10219호, 2010. 3. 31].

(Received February 7, 2013/Accepted February 26, 2013) 